\title{
Historical and Biographical Approaches towards Teachers Training in Learning Physics Using Moodle LMS
}

\author{
Fairuza M. Sabirova ${ }^{1 *}$, Viktor Y. Shurygin ${ }^{1}$, Aleksandr V. Deryagin ${ }^{1}$, Ilmir A. Sahabiev ${ }^{1}$ \\ ${ }^{1}$ Department of Physics, Kazan Federal University, Yelabuga, RUSSIA
}

Received 28 June 2018 • Revised 28 November 2018 • Accepted 4 December 2018

\begin{abstract}
This article describes the possibilities for applying the historical and biographical approaches during the blended physics courses taught by using the original electronic training courses. This article provides the original e-learning modules that were applied during the Pedagogical Education course at the Kazan Federal University in 2016-2017 and 2017-2018. The training process was based on several different thematic blocks. Survey was conducted after the success testing. This survey has revealed that the historical and biographical approaches to teaching physics by means of the MOODLE LMS allow the teachers to increase the interest not only to this course, but also to the history of its development. In percentage terms, 39.7\% of students have noted an increased level of motivation for independent activity. The original online courses will come in handy to design new physics curricula for online teaching and learning in other countries.
\end{abstract}

Keywords: education, learning physics, Moodle, history

\section{INTRODUCTION}

When it comes to the process of teaching future teachers, one has not only to teach them the basic skills, but also to foster the common culture (Deng \& Bao, 2005; McCollough \& Ramirez, 2012). This problem can be solved through the historical and biographical approaches to teaching various courses, including physics (Gay-Voronskaya, 2015). We adhere to the definition of biographical approach as a method of historical research, designed to describe, reconstruct and analyze the facts of life, outputs and a psychological portrait of an outstanding scientist (Cohen et al., 2013). Thus, information about how the famous physical laws we discovered, as well as different facts of biography, knowledge of what the effect these discoveries had on social processes and information about what role the science has in society development make the learner an involuntary participant in the processes of cognition (Chamberlayne et al., 2004). They affect and somehow shape the student's system of spiritual values. They also contribute to a deeper understanding of the significance of different physical laws (Chamberlayne et al., 2000).

It happened that there are certain specific ways to apply the historical and biographical approaches while teaching physics in schools and universities (Chen \& Sonawane, 2015; Green et al., 2012). These are the introductory/final reviews and notes of historical interest that serve as a means for substantiating new knowledge and generalizing the previously gained knowledge. However, there are other ways to introduce the historical material in physics classes: educational conferences, projects, etc. (Kubiatko \& Vaculová, 2011). In most cases, however, historical and biographical information about the history of science is introduced on a rare occasions, since the academic time is limited (Alejandro, 2017). Thus, the major focus is usually laid on learning the basic material and on the ways of its application during the process of solving physical problems and during the lab courses. Besides, teachers do not unlock the potential of innovative information technologies and Internet resources (Cunha et al., 2017; Kintu et al., 2017; Krasnova \& Shurygin, 2017). In modern conditions, historical and biographical approaches are advisable to apply by implementing the principle of blended learning, which combines both the inclass activity and independent extracurricular learning based on the e-leaning means.

(C) 2019 by the authors; licensee Modestum Ltd., UK. This article is an open access article distributed under the terms and conditions of the Creative Commons Attribution License (http://creativecommons.org/licenses/by/4.0/).

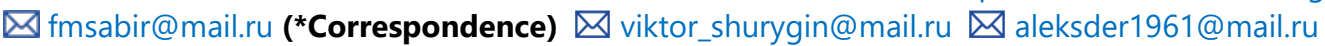




\section{Contribution of this paper to the literature}

- The possibilities for applying the historical and biographical approaches during the blended physics courses are outlined.

- The introduced program contributes to the improvement of cognitive and practical skills of handling various information sources and ICT tools.

- Developed courses will come in handy to design new physics curricula. for online teaching.

Internet technologies provide us with many useful tools that can be used to improve the teaching and learning process (Linn, 2013). When students participate in computer-based experimental activities, they acquire a deeper understanding of scientific concepts (Drigas \& Kontopoulou, 2016). E-learning platforms also allow teachers to provide students with different kind of material, as well as to interact with them in real-time (Benta et al., 2014). Teaching physics through technology allows conducting experiments that cannot be done in real laboratories. The most favorable conditions for applying the historical and biographical approaches to teaching physics are provided on the online learning platform well-known as the Modular Object-Oriented Dynamic Learning Environment (MOODLE LMS). Moodle is usually regarded as a robust, fully featured package. As an open source software, this system is being constantly revised and improved. At this point, teachers considering implementing the educational technology must carefully evaluate it before putting it to use with students (Colace et al., 2002).

Moodle is a good way for teachers to organize, manage and deliver the course material. At the instructional point, multimedia tools, designed to create attractive activities, make the learning process friendlier for students (Lópes-De-Ipiña et al., 2006). Currently, universities face a wide range of challenges, associated with the increased enrollment and tight budgets. This issue is inciting many high education institutions to apply new approaches, including the application of LMS, such as Moodle, for delivering courses to help extend teaching and learning beyond the classroom (Essel \& Wilson, 2017). These factors create sufficient grounds for designing the online courses that would include the online physics course in the MOODLE LMS (Grober et al., 2013; Limongelli et al., 2011). The possibility of developing an online course allows the students to organize their independent activities, for example - to choose and systemize the historical or biographical information about the specific physical law or phenomenon, to choose related tasks, to write abstracts on selected topics. Thus, the purpose of this research is to describe the possibilities for applying the historical and biographical approaches during the blended physics courses taught by using the original electronic training courses, designed in the Moodle LMS.

\section{METHODOLOGICAL FRAMEWORK}

\section{Participants}

The research on the application of historical and biographical approaches during the physics classes was conducted during the period of Pedagogical Education bachelors training (specialization: Mathematics and Physics) in 2016-2017 and 2017-2018 at the Kazan Federal University (Elabuga Institute). However, historical and biographical approaches have been applied to teach physics long before this time interval. The number of students, who took part in the e-course testing, have amounted to 58 (male students $-63.8 \%$, standard deviation -1.01 , female students $-36.2 \%$ ). The average age of participants is 20 years. All participants were informed about the project goals and content, as well as about all aspects regarding the research ethics. Participants have given a written permission for using their photos as a research material.

\section{Design}

The Moodle learning platform is widely used for not only distance learning, but also for blended learning. Such elements as a survey and a questionnaire are important for analyzing the results and effectiveness of this learning mode. The survey offers several answers for each question to select. The questionnaire can contain many questions of various types. The questions are asked to determine the effectiveness of the historical and biographical approaches. In this research, the e-course element called the survey is applied (Cerezo et al., 2016). The course structure was agreed with the academic administration. At the initial stage, we have resolved the issues related to the Moodle application and deploy to the university's web host. Student work was visualized by means of a computer-based virtual reality through the learning management system, designed for physics courses taught using the Moodle LMS and special software packages like interactive physics ${ }^{\circledR}$ (Germano et al., 2012). The experiments were performed remotely on a computer. A combination of hardware and software allowed the students to perform their laboratory experiments remotely by controlling the tasks via interface (Lópes-De-Ipiña et al., 2006). The course introduction covers the course program, a calendar plan, exam questions, student and teacher 
guidelines, as well as the links to open electronic and educational resources of other universities, to a news and discussion forums.

Each learning module includes the following elements: theoretical material on physics, instructional materials for lab sessions, independent work tasks, links to recommended publications available in the university library, hyperlinks to the electronic sources of information, midpoint and summative tests. The e-course material is taught in parallel with the classroom lessons. All the learning materials were available in Russian and English. The student could choose a course by clicking on the Change language icon. The theoretical course material is introduced in the form of lecture elements, when each block of information is interspersed with test questions. If the answer is wrong, the system switches the student back to re-learn the theory. Besides, the block includes presentations, animations and videos useful in learning specific issues. The teacher designs the specific test based on the assignments that were designed earlier. The test can be configured in the training and the assessment modes.

\section{Research Instruments}

Special questionnaire was conducted after 6 months of using Moodle. The goal of this survey was to collect first impression about the system and concerns on the system design and introduced learning modules. The questionnaire included six questions with five options for each that were reflecting different degrees of satisfaction with the quality of the learning process. The testing was carried out after the final exams at the Kazan Federal University. There were no irrelevant answer forms. One teacher and one psychologist have attended the survey. Before the procedure, we have informed the students that diagnosis results would be confidential. We have asked the subjects to answer sincerely and truthfully, and to write any symbol or sign in the "subject" column of the registration form. Statistical data analysis was carried out with the IBM SPSS Statistics 22.

\section{RESULTS}

Any physics course has several units describing the corresponding physical theories, phenomena and laws. According to the teaching experience, each unit should be expanded with historical and biographical material that would reveal the features of any concept development. There are lectures provided for by specific course units and presenting (in an understandable form) not only the basic ideas of a specific theory, law or concept, but also the peculiarities of a historical period, when they were formulated or discovered. At this point, such lectures present not only the names of related scientists, but also an additional information (their worldview or the political situation). The problems containing certain history-related elements are stated and solved during the practical sessions. Future physics teachers include the biographical information into their course and final papers, devoted to a particular physical phenomenon, theory, law.

For example, the Mechanics unit should end with the conclusion taken from the History of Mechanics Origin and Development unit, which would reveal that mechanics is one of the oldest sciences bind with the society demands. Future teachers must study in detail the life and work of scientists living in different periods (as Archimedes, Copernicus, Kepler, Galileo, and Newton). The same should be done when learning other units. Thus, Molecular Physics and Thermodynamics unit should be taught with a focus laid on that the idea of atomism was introduced by the natural philosophers of the Ancient Greece (Democritus, Leucippus, and Epicurus). Further study of matter and thermal phenomena is associated with the scientific studies conducted by R. Maier, J. Joule, G. Helmholtz, S. Carnot, R. Clausius, L. Boltzmann.

As for the Electrodynamics unit, students should learn not only the historical information about the research on electrical and magnetic phenomena, but also about the interaction of fundamental scientific ideas and their technical applications. This goes for the Maxwell and his theory of the electromagnetic field. Particular attention should be paid to such course units as the Quantum Physics and the Physics of Atom and Atomic Nucleus, since they are more difficult to learn because of the specific features that the research objects have. One obviously cannot apply the concepts and principles of classical physics to describe the phenomena of the micro-world, since its laws are rather scholastic than deterministic. At this point, introducing such a concept as a quantum is a significant step. In our opinion, these features and a complex mathematical apparatus are the reasons why the historical and biographical approaches are at the forefront of teaching these units. At the same time, the focus should be laid on the biographies and achievements of JJ. Thomson M. Planck, E. Rutherford, A. Einstein, N. Bohr, the Curie couple, and E. Fermi. The teacher should point out to the fact that almost all the achievements in this field were awarded the most prestigious award - the Nobel Prize. Thus, the teacher, presenting the laws of quantum mechanics, usually pays much attention to the history of the quantum science development. Such a style of narration with historical details at the core creates intrigue and attracts student's attention to the physical significance of natural phenomena, since such a manner of teaching meets the knowledge continuity, Bohr's correspondence and the historicism principles. 
Table 1. Fundamental Developments and Discoveries in Quantum Physics

\begin{tabular}{|c|c|}
\hline Scientist & Developments and Discoveries \\
\hline $\begin{array}{l}\text { Gustav Robert } \\
\text { Kirchhoff } \\
(1824-1887)\end{array}$ & $\begin{array}{l}\text { German physicist, who proposed his law of thermal radiation in } 1859 \text {. He was the one to introduce the } \\
\text { concept of a black body. }\end{array}$ \\
\hline & $\begin{array}{l}\text { strian physicist and mathematician, who } \\
\text { Itzmann also theoretically substantiated }\end{array}$ \\
\hline $\begin{array}{l}\text { Joseph John } \\
\text { Thomson } \\
(1856-1940) \\
\end{array}$ & $\begin{array}{l}\text { English physicist, who discovered the electron in } 1897 . \text { He introduced the first model of an atom as a sphere } \\
\text { of positive charge with floating electrons in it. He received the Nobel Prize in Physics in } 1906 .\end{array}$ \\
\hline $\begin{array}{l}\text { Max Karl Ernst } \\
\text { Ludwig Planck } \\
(1858-1947) \\
\end{array}$ & $\begin{array}{l}\text { German theoretical physicist, who laid the foundation of the Quantum Theory by postulating in } 1900 \text { that } \\
\text { energy can be emitted or absorbed by matter only in small, discrete units called quanta. He received the } \\
\text { Nobel Prize in Physics in } 1918 \text {. }\end{array}$ \\
\hline $\begin{array}{l}\text { Ernest Rutherford } \\
(1871-1937)\end{array}$ & $\begin{array}{l}\text { British physicist and the father of nuclear physics, who pioneered the Rutherford model of the atom. He } \\
\text { discovered a proton in 1919. He received the Nobel Prize in Chemistry in } 1908 .\end{array}$ \\
\hline $\begin{array}{l}\text { ohrik } \\
\text { ohr }(1885\end{array}$ & $\begin{array}{l}1913, \text { he postulated the conditions for } \\
22 .\end{array}$ \\
\hline $\begin{array}{l}\text { es } \\
\text { ck } \\
1974)\end{array}$ & $\begin{array}{l}\text { English physicist, who discovered the electron in } 1932 \text { by proje } \\
\text { target. He received the Nobel Prize in Physics in } 1935 .\end{array}$ \\
\hline $\begin{array}{l}\text { Alber } \\
(1879\end{array}$ & $\begin{array}{l}\text { A world-famous theoretical physicist, who provided an extension of the Planck's quantum hypothesis and } \\
\text { explained the photoelectric effect. He determined a formula for the photoelectric effect. He received the } \\
\text { Nobel Prize in Physics in 1921. He is the developer of several more significant physical theories, such as the } \\
\text { special theory of relativity (1905); the general theory of relativity (1907-1916); the quantum theory of heat } \\
\text { capacity. He also predicted the existence of gravitational waves. }\end{array}$ \\
\hline-1958$)$ & $\begin{array}{l}\text { Swiss theoretical physicist, who made a decisive contribution to science through the exclusion principle or } \\
\text { Pauli principle (1925). He received the Nobel Prize in Physics in } 1945 .\end{array}$ \\
\hline $\begin{array}{l}\text { Werner Karl } \\
\text { Heisenberg } \\
(1901-1976)\end{array}$ & $\begin{array}{l}\text { German theoretical physicist, who elaborated the matrix formulation of quantum mechanics in collaboration } \\
\text { with the Max Born (1925). In 1927, he developed the uncertainty principle, which states the connection } \\
\text { between the momentum and coordinates of a microparticle caused by its corpuscular-wave nature. In 1928, } \\
\text { Heisenberg and P. A. M. Dirac put forward the idea of the exchange interaction. In 1929, Heisenberg and } \\
\text { Pauli were building the theory of quantum electrodynamics. He received the Nobel Prize in Physics in } 1932 .\end{array}$ \\
\hline $\begin{array}{l}\text { Louis de Broglie } \\
(1892-1987) \\
\end{array}$ & $\begin{array}{l}\text { French physicist, who pitched an idea in } 1923 \text { that all matter has wave properties. This idea has triggered off } \\
\text { the wave mechanics development. He received the Nobel Prize in Physics in } 1929 .\end{array}$ \\
\hline $\begin{array}{l}\text { Erwin Rudolf Josef } \\
\text { Alexander } \\
\text { Schrödinger }\end{array}$ & $\begin{array}{l}\text { formulated the type of differential equation known as a wave equation, which serves } \\
\text { del of the movement of waves. He received the Nobel Prize in Physics in } 1933 .\end{array}$ \\
\hline $\begin{array}{l}\text { Paul Adrien } \\
\text { Maurice Dirac } \\
(1902-1984) \\
\end{array}$ & $\begin{array}{l}\text { English theoretical physicist, who proved that in relativistic wave mechanics, the wave function must have } \\
\text { four components (three coordinates and time) that are governed by the system of four partial differential } \\
\text { equations. He received the Nobel Prize in Physics in } 1933 \text {. }\end{array}$ \\
\hline
\end{tabular}

Such a job, however, is being done on a rare occasions, since the academic time is limited and the teachers are little prepared. The combination of traditional teaching modes (lectures, practical and laboratory sessions) with the online courses will allow the students to apply the historical and biographical approaches regularly. The structure of the original electronic physics/astronomy course, designed with the Moodle LMS, contains a number of elements intended for applying the historical and biographical approaches. As a matter of priority, this is the Outstanding Scientists database, filled by the students themselves during the learning process. The students independently learn the history of the scientific thought and the biographies of scientists, who have made a significant contribution to the relevant branch of physics. Thus, Table 1 presents the result of a collective research conducted by the thirdyear students learning the Quantum Physics and the Physics of Atom and Atomic Nucleus units.

The scientists are listed as they are learnt during the course. Therefore, the list is totally filled only at the end of the course. In this regard, students choose the appropriate literature according to the teacher's instruction, but in modern conditions, they often turn to Internet resources in order to find the necessary information about scientists. They choose the most interesting and understandable sources in among many others (Figure 1). 


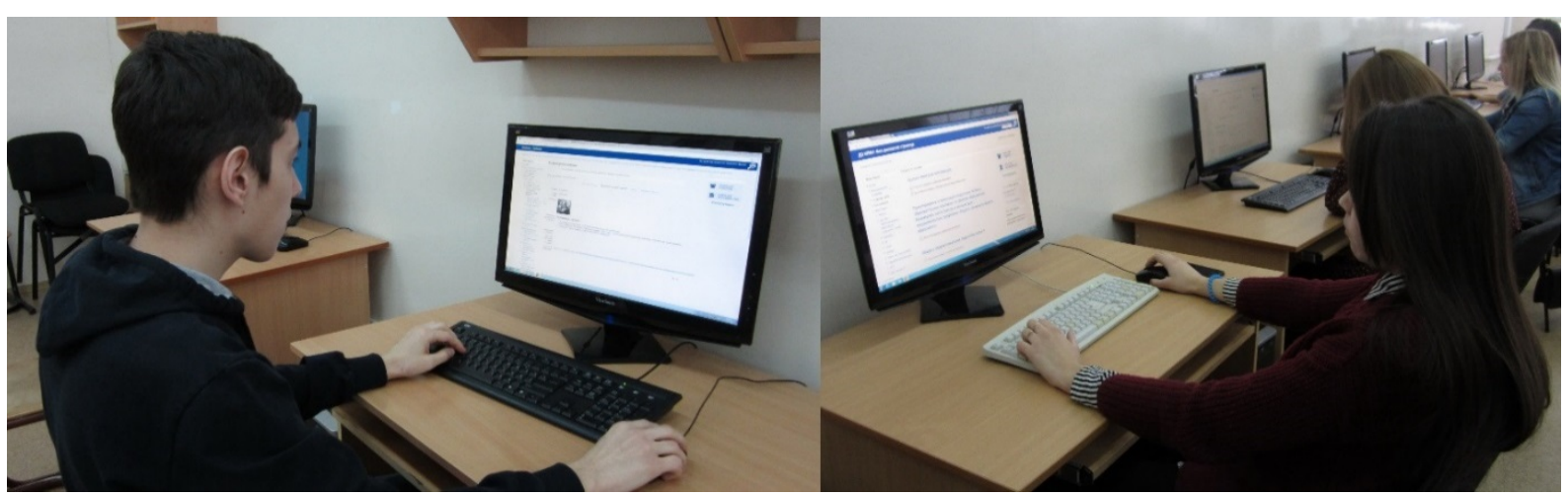

Figure 1. Students handling the databases

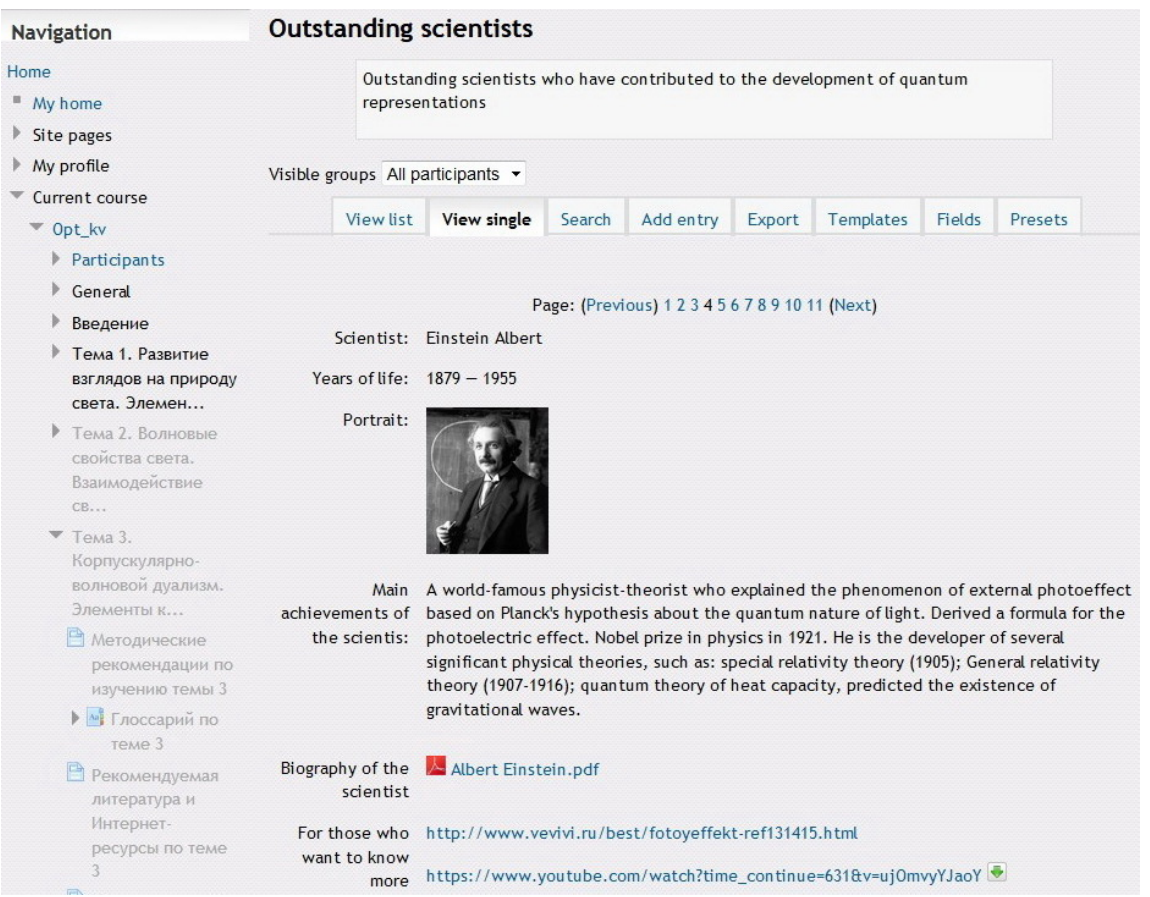

Figure 2. Database Course Unit Page

Thus, the database is expanded with information that is more extensive. The choice of historical and biographical information to add is not random. Students make a kind of a guide to the network with links attached. Both teachers and students can add and edit their materials (Figure 2).

A video compilation, related to the history and the modern state of physics, is generated by Wiki and replenished by students during the course. This collection was created by students and evaluated by the teacher. Besides, students were asked to write an essay on any proposed topic, for example - on the history of insights into the micro-world. A teacher offered the related topics in the forum (Figure 3). 


\section{News forum}

\section{Subjects of research work on discipline}

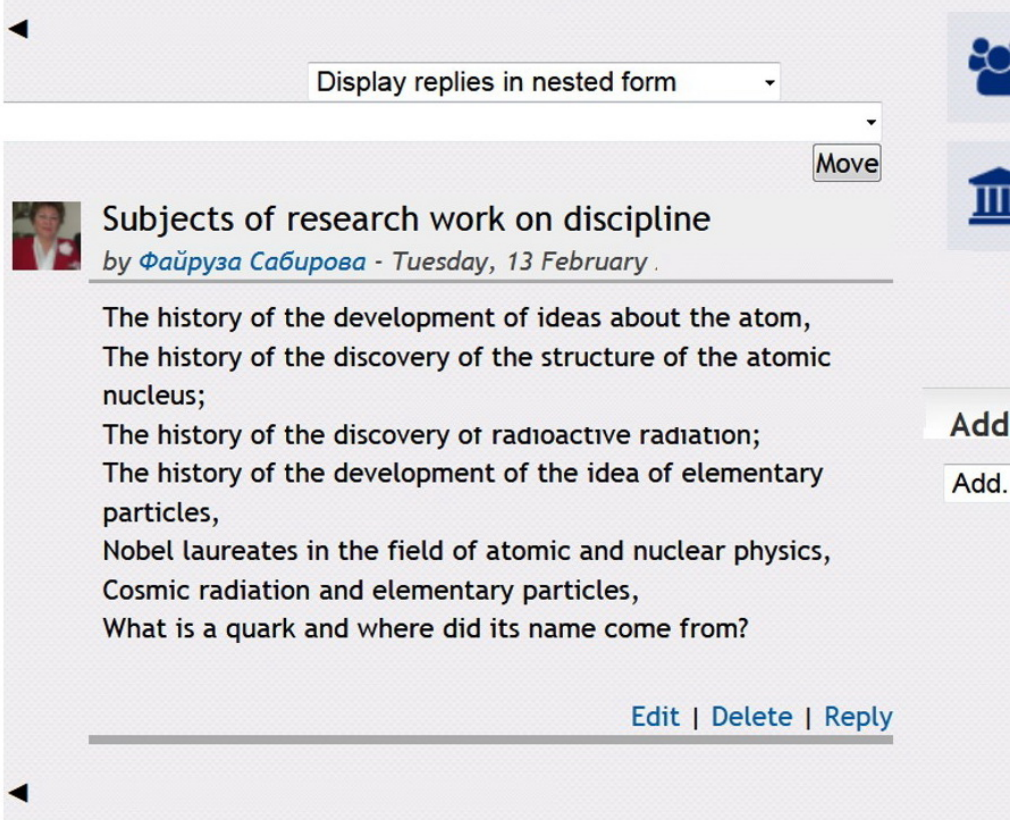

Figure 3. Research Topics in Physics on the Forum

Table 2. Student Survey Results at the End of the Quantum Physics and the Physics of Atom and Atomic Nucleus Courses

\begin{tabular}{llccccc}
\hline Introduced historical and biographical & \multicolumn{1}{c}{$\begin{array}{c}\text { Strongly } \\
\text { information }\end{array}$} & Agree & Not Sure & Disagree & $\begin{array}{c}\text { Strongly } \\
\text { Disagree }\end{array}$ \\
\hline 1 & Increases the interest to the course & 24 & 28 & 5 & - & - \\
\hline 2 & Channels the course into humanities & 22 & 33 & 1 & 1 & - \\
\hline 3 & Contributes to deeper learning & 19 & 26 & 6 & - & - \\
\hline 4 & $\begin{array}{l}\text { Allows gaining additional knowledge } \\
\text { from different branches of science }\end{array}$ & 25 & 28 & 3 & 1 & - \\
\hline 5 & Motivates to individual activity & 2 & 21 & 3 & 2 & - \\
\hline 6 & Allows aligning oneself with the Internet & 19 & 27 & 7 & 5 & - \\
\hline
\end{tabular}

Naturally, the student, who reveals the content of each topic, learns not only about the history of discoveries, but also about the scientists, who made them. The prepared abstracts were added to the electronic course through the Seminar element. At first, the students-reviewers should evaluate the job. The teacher brings his/her verdict after the discussion. The individual work problems and the question poll also contain tasks related to the history of physics. Student are also involved into the process of selecting tasks. At the final stage, students were offered a quiz. Its goal was to find out the students' opinion on the introduced online course. The testing was carried out after the participants had completed the training and passed the exam. The results are shown in Table 2.

Thus, the majority of students noted that historical and biographical approaches are a required element of teaching the future physics teachers. The main argument for their application is that they channel the learning process into humanities. Besides, $79.3 \%$ respondents agreed that the online course has contributed to the computer skills development. Another 25 future teachers pointed to the multi directionality and complementarity of the course modules. None of the students recognized the online course negatively.

\section{DISCUSSIONS}

One can note that e-learning is kind of interactive type of activity. Thus, social media sites are sometimes regarded as dominant platforms for both education and entertainment. Both teachers and students can follow the news, technical innovations, music, art, share thoughts, knowledge, ideas or media via Twitter or Facebook (Jones \& Bogle, 2017). What is interesting is that an effort on replacing the LMS with Facebook Groups as a course website without the instructor was already been discussed. The following paper not only defined the features that a LMS must have to be efficient, but also the academic capabilities that it should have. One of the biggest pros of MOODLE LMS is its possibility to facilitate communication. This platform supports the exchange of files between teachers 
and students. Mailing service allows instant informing all participants of the course or selected groups of current events (Shurygin \& Krasnova, 2016). Moreover, there is a potential to determine the causation between LMS usage and student's performance.

Another important issue concerns directly the features of physics education. There are many experiments that could help learners to understand the physical concepts, nut cannot be performed in real laboratories because they are very dangerous, expensive, and very complex and take a long time (Drigas \& Kontopoulou, 2016). Therefore, students must be motivated and encouraged for conceptual change during the learning process. They should gain a more exciting experience our findings correlate with the observation sessions, carried out with the second-year students of the University of St Andrews in Scotland. The introduction online course for quantum mechanics has contributed to quick data collection, so students could compare the experimental values and theoretical predictions and understand their connection (Kohnle et al., 2013). The Technical University of Madrid has placed at lecturers' disposal the Moodle platform to develop online courses as a complement to the in-class lessons. The majority of students have taken the web-based homework testing in a positive light. Moreover, there was a significant improvement in outcomes (Martín-Blas \& Serrano-Fernández, 2009). The obtained results encourage us to continue with the improvement of our Moodle virtual space. Further research can be focused on a more detailed study of performance within the context of designed online courses application.

\section{CONCLUSION}

To sum up, this article provides the results of blended learning of physics through the original online and the traditional learning modes. Student survey analysis (58 students of the Kazan Federal University) has revealed that the historical and biographical approaches, applied during the blended course taught by means of the Moodle LMS, improve the quality of teaching physics. Thus, they allow channeling the teaching and learning process into humanities, increasing the interest of students to learn not only physics, but also the history of its development. Web browsing contributes to a higher level of subject knowledge systematization through both the intrasubject and the interdisciplinary relationships that illustrate the course ties with other sciences in the course of their development. The introduced program contributes to the improvement of cognitive and practical skills of handling various information sources and ICT tools while searching for historical and biographical information. Besides, online courses have created the prerequisites for sparking the independent activity of students. The submissions can be useful as a basis for creating new online training curricula in physics for pedagogical universities.

\section{REFERENCES}

Alejandro, C. (2017). Tensions and challenges in the use of the biographical method. Retrieved from https:/ / philpapers.org/rec/CAPTAC-2

Benta, D., Bologa, G., \& Dzitac, I. (2014). E-learning platforms in higher education, Case study. Procedia Computer Science, 31, 1170-1176. https:// doi.org/10.1016/j.procs.2014.05.373

Cerezo, R., Sánchez-Santillán, M., Paule-Ruiz, M. P., \& Núñez, J. C. (2016). Students' LMS interaction patterns and their relationship with achievement: A case study in higher education. Computers $\mathcal{E}$ Education, 96, 42-54. https:/ / doi.org/10.1016/j.compedu.2016.02.006

Chamberlayne, P., Bornat, J., \& Apitzsch, U. (Eds.) (2004). Biographical methods and professional practice: An international perspective. Policy Press. https://doi.org/10.2307/j.ctt1t89d2j

Chamberlayne, P., Bornat, J., \& Wengraf, T. (Eds.). (2000). The turn to biographical methods in social science: Comparative issues and examples. Psychology Press

Chen, Z., \& Sonawane, S. (2015). The new concept definition and analysis of biographical researching method. Scholarly Research Journal's, 3(19), 352-359.

Cohen, L., Manion, L., \& Morrison, K. (2013). Research methods in education. Routledge. https:/ / doi.org/10.4324/9780203720967

Colace, F., Santo, M. D., \& Vento, M. (2002). Evaluating on-line learning platforms: a case study. Paper presented at the 36th Hawaii International Conference of System Sciences. Big Island, Hawaii.

Cunha, M. P., Lewis, M., Rego, A., \& Smith, W. K. (2017). Biographical methods in leadership research. Handbook of Methods in Leadership Research, 372. https:/ / doi.org/10.4337/9781785367281.00024

Deng, T., \& Bao, C. (2005). A Renewedly Understanding and Constructing of Teachers' Culture: Commentary on Andey Hargreaves's Perspective of Teachers' Culture. Studies in Foreign Education, 8, 002.

Drigas, A., \& Kontopoulou, M. T. L. (2016). ICTs based Physics Learning. International Journal of Engineering Pedagogy (iJEP), 6(3), 53-9. https://doi.org/10.3991/ijep.v6i3.5899 
Essel, D. D., \& Wilson, O. A. (2017). Factors Affecting University Students' Use of Moodle: An Empirical Study Based on TAM. International Journal of Information and Communication Technology Education (IJICTE), 13(1), 14-26. https:/ / doi.org/10.4018/IJICTE.2017010102

Gay-Voronskaya, A. (2015). Biographic Method and its Heuristic Potential in Sociological Research. Retrieved from http:/ / elib.bsu.by/bitstream/123456789/8636/1/.pdf

Germano, J. S. E., Pinheiro, D. M., Brunelli, D. D., \& Murakami, G. (2012). Simulation Programs can the Teacher Assist in a Classroom? A Case Study of the Interactive Physics Program used in Mechanical Oscillations. Journal of Physics Teaching, 31.

Green, J. L., Camilli, G., \& Elmore, P. B. (Eds.) (2012). Handbook of complementary methods in education research. Routledge.

Grober, S., Eckert, B., \& Jodl, H. J. (2013). A New Medium for Physics Teaching: Results of a Worldwide Study of Remotely Controlled Laboratories (RCLs). European Journal of Physics, 35(1), 018001. https://doi.org/10.1088/0143-0807/35/1/018001

Jones, R. A., \& Bogle, S. A. (2017). An Investigation of the Use of Facebook Groups as a Learning Management System to Improve Undergraduate Performance. In Proceedings of the World Congress on Engineering and Computer Science.

Kintu, M. J., Zhu, C., \& Kagambe, E. (2017). Blended learning effectiveness: the relationship between student characteristics, design features and outcomes. International Journal of Educational Technology in Higher Education, 14(1), 7. https:/ / doi.org/10.1186/s41239-017-0043-4

Kohnle, A., Baily, C., Hooley, C., \& Torrance, B. (2013). Optimization of simulations and activities for a new introductory quantum mechanics curriculum. arXiv preprint arXiv: 1307.1483.

Krasnova, L.A., \& Shurygin, V.Y. (2017). Development of teachers' information competency in higher education institution. Astra Salvensis, 5(10), 307.

Kubiatko, M., \& Vaculová, I. (2011). Project-based learning: characteristic and the experiences with application in the science subjects. Energy Education Science and Technology Part B: Social and Educational Studies, 3(1), 65-74.

Limongelli, C., Sciarrone, F., \& Vaste, G. (2011). Personalized e-learning in Moodle: the Moodle LS System. Journal of e-Learning and Knowledge Society, 7(1), 49-58.

Linn, M. C. (2013). Internet environments for science education. Routledge.

Lópes-De-Ipiña, D., García-Zubia, J., \& Orduña, P. (2006). Second IEEE International Conference on e-Science and Grid Computing. IEEE, 123.

Martín-Blas, T., \& Serrano-Fernández, A. (2009). The role of new technologies in the learning process: Moodle as a teaching tool in Physics. Computers $\mathcal{E}$ Education, 52(1), 35-44. https:/ / doi.org/10.1016/j.compedu.2008.06.005

McCollough, C., \& Ramirez, O. (2012). Cultivating culture: Preparing future teachers for diversity through family science learning events. School Science and Mathematics, 112(7), 443-451. https://doi.org/10.1111/j.19498594.2012.00158.x

Shurygin, V. Y., \& Krasnova, L. A. (2016). Electronic Learning Courses as a Means to Activate Students' Independent Work in Studying Physics. International Journal of Environmental and Science Education, 11(8), 1743-1751.

\section{http://www.ejmste.com}

